\title{
Influences of COVID-19 pandemic lockdown on excess lifetime cancer risk value of natural radiation
}

\author{
Akbar Abbasi $^{1}$ (D) Fatemeh Mirekhtiary ${ }^{2} \cdot$ A. El-Denglawey ${ }^{3} \cdot$ Hesham M. H. Zakaly $^{4,5}$
}

Received: 21 April 2021 / Accepted: 14 July 2021 / Published online: 27 July 2021

(c) Akadémiai Kiadó, Budapest, Hungary 2021

\section{Abstract}

This study focuses on the consequences of the COVID-19 pandemic on annual effective doses and excess lifetime cancer risk values due to ionizing radiation and radon which has been reported UNSCEAR 2000. The random data collection questionnaire method was applied to assess the indoor and outdoor occupancy factor for three age groups during the epidemic in Turkey. The results indicated age group C (Age $>65 \mathrm{y}$ ) has more influence from pandemic indoor and outdoor occupancy factor. As compared to before pandemic data in study area and global average exposure to natural radioactive sources.

\section{Graphic abstract}

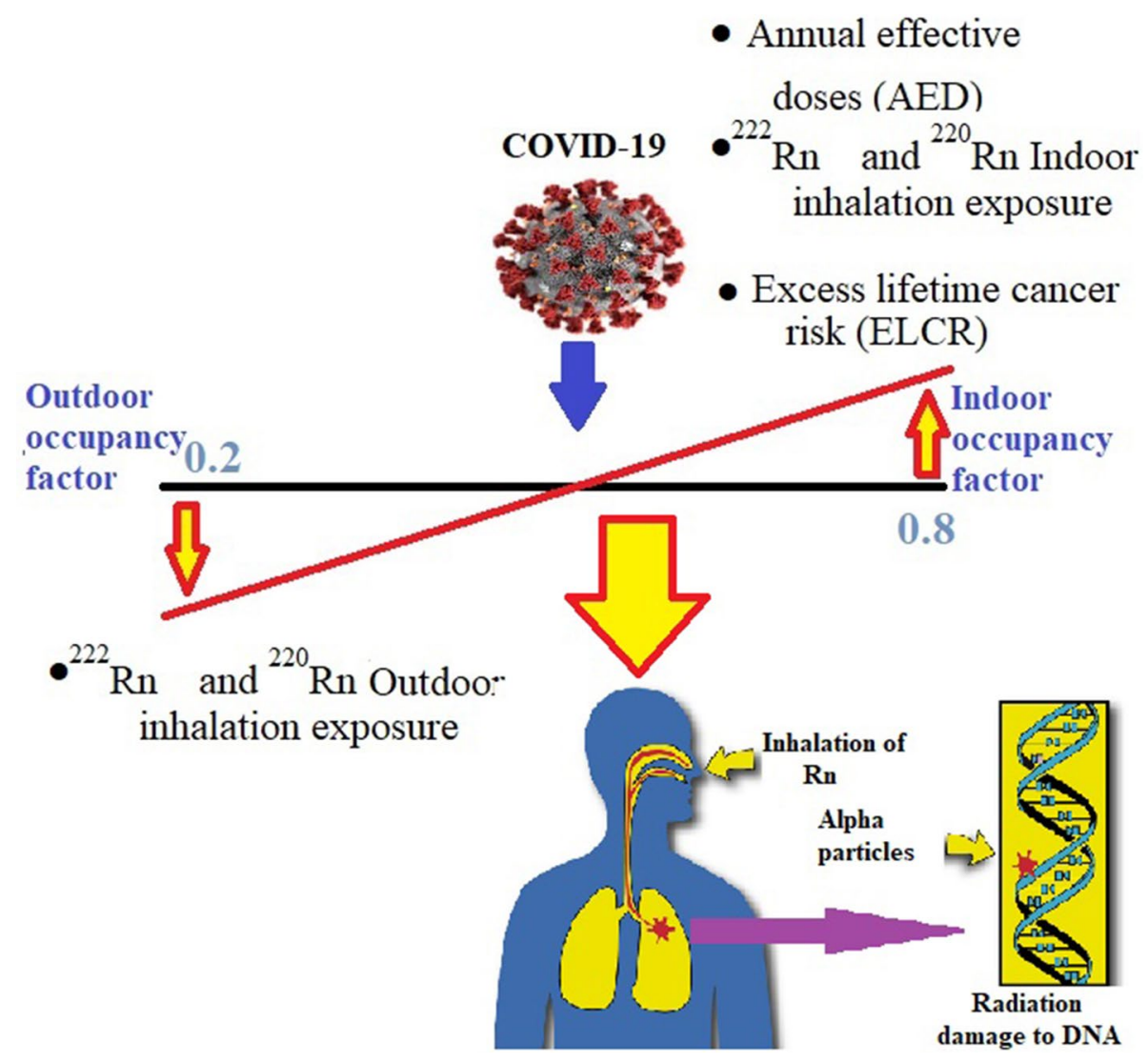

Keywords Annual effective doses $\cdot$ ELCR $\cdot$ Occupancy factor $\cdot$ Lockdown effect on health $\cdot$ COVID-19

Extended author information available on the last page of the article 


\section{Introduction}

In December 2019, coronavirus disease 2019 (COVID19) pneumonia first occurred in Wuhan, China [1]. Then quickly spread around the world. Since then, the global health organization (WHO) is trying to figure out what was going on with the COVID-19 epidemic and what can be done to minimize the rate of transmission to healthy people. In this difficult situation, each nation is implementing various strategies to prevent and monitor the spread of coronavirus among its citizens. Many countries have already implemented massive policies, with state or government lockout being one of the most common. By April 5, 2021, COVID-19 had killed 2.85 million people worldwide [2]. Different countries adopted various lockout policies to protect public health by limiting citizen movement. On March 11, 2020, the Turkish Ministry of Health confirmed the first case of COVID-19 in Istanbul, Turkey. On March 12, 2020, the Turkish government announced the first restrictions to limit citizen mobility; schools were closed beginning March 16, 2020, sporting activities were cancelled, and state officers were restricted from traveling abroad until further notice. The ease on lockdown continued during winter and due to a high number of new cases, the new restriction on March 12, 2021.

The COVID-19 pandemic has brought about sudden and significant changes to people's lifestyles. Those effects are including the imposed isolation of individuals nationally and locally, illnesses caused by the virus, and health risk. One of the most significant issues from a radiological view on people's health risk is the amount of time they are exposed to radon gas. Whereas, in normal lifestyle, people, especially young people, spend more time outdoors for work, fun and entertainment.

UNSCEAR was given the formula for calculating annual effective dose (AED) values, and this formula is used all over the world to measure AED values. Consequently, the excess lifetime cancer risk (ELCR) is another standard risk evaluation parameter which in UNSCEAR has been presented method for calculation [3]. Indoor gamma dose rate and radon exposure values are typically higher than outdoor gamma dose rate values, except in a few countries or regions around the world, according to several surveys $[4,5]$.

During the lockdown, radon exposure, which is the leading cause of natural ionizing radiation exposure and the second leading cause of lung cancer in confined spaces, can have an effect on the outcome of certain diseases developing [6]. Some studies have also presented the ${ }^{222} \mathrm{Rn}$ concentration and radiological risk in building materials $[7,8]$ and gamma radiation dose in building materials $[7,9,10]$.

The objectives of this study were to estimate the effect of the lockdown period to AED and ELCR values of the natural gamma radiation dose rate and ${ }^{222} \mathrm{Rn}$ exposure for three categories: group A (Age $<10 \mathrm{y}$ ), group B (10 $\mathrm{y}<$ Age $<65 \mathrm{y})$, and group C (Age $>65 \mathrm{y})$.

\section{Material and methods}

To calculate the outdoor and indoor occupancy factors for the gamma radiation dose, all researchers usually used the formulas to calculate effective doses per annum (AED), and ELCR values reported by UNSCEAR $[3,11]$. The effective doses per annum $\left(\mathrm{mSv} \mathrm{y}^{-1}\right)$ were calculated using the Eq. (1):

$A E D($ indoor/outdoor $)=D($ indoor/outdoor $) \times T \times C C \times O F$

where $\mathrm{D}$ is the absorbed dose rate $\left(\mathrm{nGy} \mathrm{h}^{-1}\right), \mathrm{T}$ is time in hour for 365 days $(8760 \mathrm{~h})$, and $\mathrm{CC}$ is conversion coefficient $\left(0.7 \mathrm{~Sv} \mathrm{~Gy}^{-1}\right)$ [12]; OF is occupancy factor of 0.8 and 0.2 for indoor and outdoor exposure, respectively.

The excess lifetime cancer risk (ELCR) is a formula that calculates the lifetime cancer risk for any population due to ionizing radiation exposure. The following equation was used to compute ELCR for population [3]:

$E L C R=A E D \times R F \times D L$

where RF is the risk factor that determines the fatal cancer risk per sievert, and DL is the average lifetime duration (70 years). The International Commission on Radiological Protection (ICRP) recommends a value of 0.057 for public exposure due to stochastic effects. [13].

The average radon concentration value from radon map throughout of Turkey was considered. In this report, the average radon concentration value in overall of Turkey was $57 \mathrm{~Bq} \mathrm{~m}^{-3}$ [14], which higher than the radon concentration world average value $\left(30 \mathrm{~Bq} \mathrm{~m}^{-3}\right)$.

The UNSCEAR report [15] applied the following equation to measure the annual effective dose (D) due to indoor radon. This equation gives the annual effective dose value which exposure by indoor radon concentration to people $[3,16]$ :

$A E D_{R n}\left(\mathrm{mSv} \mathrm{y}^{-1}\right)=C \times E q F \times T \times D C F \times O F$

here $\mathrm{C}$ is the indoor radon concentration (Turkey average is $\left.57 \mathrm{~Bq} \mathrm{~m}^{-3}\right)$ [14], $E q F$ is the radon and its progenies equilibrium factor (0.4), $T$ is the number of hours in a year $(8760 \mathrm{~h}$ $\left.\mathrm{y}^{-1}\right)$, and DCF is the dose conversion factor $\left(6.7 \mathrm{nSv} / \mathrm{Bq} \mathrm{m}^{-3}\right)$, $\mathrm{OF}$ is the occupancy factor.

The excess lifetime of LC risk (ELCR) attributable to indoor radon exposure is calculated as follows:

$E L C R=A E D_{R n} \times R F \times D L$

where $A E D_{R n}$ is radon annual effective dose $\left(\mathrm{mSv} \mathrm{y}^{-1}\right)$, $\mathrm{DL}$ is the average lifetime duration (70 years), and RF is the 
risk factor that gives the fatal cancer risk per sievert due to indoor radon concentration, which is 0.05 as per International Commission on Radiation Protection (ICRP 1993).

Beginning from April 3, 2020, Turkey's government further applied a temporary lockdown on children and young people under the age of 20 and over 65 years old [17]. A random data collection questionnaire was used to assess the occupancy factor during the epidemic in Turkey. The questionnaire sheet was performed randomly between 218 families with multiple choice questions about age groups and time spending indoor place. Participants in the evaluation were divided into three groups: (A group) children under 10 years of age, (B group) adults under the age of 65 , and ( $\mathrm{C}$ group) adults over 65 years of age. The results have shown that from the beginning of the pandemic to the study (11 March 2020 to 11 April 2021), more than $90 \%$ of those evaluated in each of the three groups (A, B, and C) spent outside the home about an hour, $2 \mathrm{~h}$ and half an hour, respectively. It indicated that out of $8760 \mathrm{~h}$ in a year, group A people utilize $365 \mathrm{~h}$ outside of houses. Whereas group B and $\mathrm{C}$ people only spent $730 \mathrm{~h}$ and $182.5 \mathrm{~h}$ outside homes during 1 year. The uncertainties were calculated from volunteers answer sheets which didn't select accurate option and they gave approximate answer for time. The obtained data was applied to modify the annual effective dose rate in 2020 and 2021. Besides, the effect of this data adjustment on excess lifetime cancer risk (ELCR) was investigated.

\section{Results and discussion}

The occupancy factor variation, annual effective dose values and excess lifetime cancer risk were calculated and presented in Table 1.

Table 1 The occupancy factor (OF), Absorbed dose rate (D), outdoor and indoor annual effective dose due to terrestrial gamma radiation, ${ }^{222} \mathrm{Rn}$ and ${ }^{220} \mathrm{Rn}$ inhalation exposure, and excess lifetime cancer risk

\begin{tabular}{|c|c|c|c|c|c|c|c|c|c|}
\hline \multirow[t]{2}{*}{ Category } & \multicolumn{2}{|c|}{ Occupancy factor (OF) } & \multicolumn{2}{|c|}{$\begin{array}{l}\text { Absorbed dose } \\
\text { rate }\left(\mathrm{nGy} \cdot \mathrm{h}^{-1}\right)\end{array}$} & \multicolumn{2}{|c|}{$\begin{array}{l}\text { Extra annual effective } \\
\text { dose in terrestrial gamma } \\
\text { radiation }\left(\mathrm{mSv} \mathrm{y}^{-1}\right)\end{array}$} & \multicolumn{2}{|c|}{$\begin{array}{l}\text { Inhalation exposure } \\
\left(\mathrm{mSv}^{-1}\right)\end{array}$} & \multirow[t]{2}{*}{$\begin{array}{l}\text { Excess lifetime } \\
\text { cancer risk } \\
(\text { ELCR }) \times 10^{-4}\end{array}$} \\
\hline & Outdoor & Indoor & Outdoor & Indoor & Outdoor & Indoor & ${ }^{222} \mathrm{Rn}$ & ${ }^{220} \mathrm{Rn}$ & \\
\hline Group A $($ Age $<10$ y) & $0.04 \pm 0.003$ & $0.96 \pm 0.05$ & - & - & $0.02 \pm 0.004$ & $0.49 \pm 0.06$ & $1.38 \pm 0.05$ & $0.12 \pm 0.01$ & $2.95 \pm 0.01$ \\
\hline $\begin{array}{l}\text { Group B }(10 \\
\mathrm{y}<\text { Age }<65 \mathrm{y})\end{array}$ & $0.08 \pm 0.005$ & $0.92 \pm 0.04$ & - & - & $0.03 \pm 0.005$ & $0.47 \pm 0.05$ & $1.32 \pm 0.08$ & $0.11 \pm 0.01$ & $2.94 \pm 0.01$ \\
\hline Group C (Age > 65 y) & $0.02 \pm 0.001$ & $0.98 \pm 0.07$ & - & - & $0.01 \pm 0.002$ & $0.50 \pm 0.04$ & $1.41 \pm 0.09$ & $0.12 \pm 0.01$ & $2.96 \pm 0.01$ \\
\hline $\begin{array}{l}\text { Turkey average (before } \\
\text { pandemic) }\end{array}$ & 0.2 & 0.8 & 65 & 75 & 0.07 & 0.36 & 1.07 & - & 2.45 \\
\hline Average worldwide ${ }^{a}$ & 0.2 & 0.8 & 57 & 75 & 0.07 & 0.41 & 1.15 & 0.10 & 2.9 \\
\hline
\end{tabular}

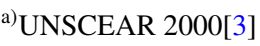

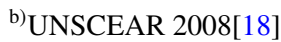

As shown in Table 1, the outdoor occupancy factor for group $\mathrm{A}$, group $\mathrm{B}$, and group $\mathrm{C}$ was obtained $5,2.5$, and 10 times less than the worldwide average, respectively (Fig. 1). In contrast, the indoor occupancy factor for group A, group $\mathrm{B}$, and group $\mathrm{C}$ were calculated 1.2, 1.1, and 1.3 times more than the worldwide average, respectively (Fig. 2). According to the absorbed dose rate worldwide average, the extra annual effective dose due to terrestrial gamma radiation was estimated. The results showed that the minimum and maximum annual effective outdoor dose were related to group $\mathrm{C}\left(0.01 \pm 0.002 \mathrm{mSv}^{-1}\right)$ and group B $(0.03 \pm 0.005 \mathrm{mSv}$ $\left.\mathrm{y}^{-1}\right)$, respectively. In contrast, the minimum annual effective dose of indoor was obtained to group B $(0.47 \pm 0.05 \mathrm{mSv}$ $\mathrm{y}-1)$, and the maximum annual effective dose of indoor was group $\mathrm{C}\left(0.50 \pm 0.04 \mathrm{mSv} \mathrm{y}^{-1}\right)$. Figure 3 shown the variation of outdoor occupancy factor during pandemic lockdown period from normal condition (before pandemic) outdoor occupancy factor in three age groups as percentage. The outdoor annual effective dose rate was obtained $70 \%, 57 \%$, and $85 \%$ less than the worldwide average for group A, group B, and group C, respectively (Fig. 3). The indoor occupancy factor variation during pandemic lockdown were compared with the reference indoor occupancy factor of normal condition (0.8) for three age groups. In this comparison, the indoor occupancy factor of group A, group B, and group C were calculated $16 \%, 12 \%$, and $18 \%$ higher than the reference indoor occupancy factor (Fig. 4).

According to the UNSCEAR report in 2008, [18], As a global average, the annual effective dose from natural radiation sources is estimated to be $2.4 \mathrm{mSv}$. In contrast, the amounts of thoron and radon are 0.1 and $1.2 \mathrm{mSv}$, respectively. The variations of ${ }^{222} \mathrm{Rn}$ and ${ }^{220} \mathrm{Rn}$ from worldwide average inhalation exposure values during lockdown are shown in Fig. 5a, b, respectively. The differences between ${ }^{222} \mathrm{Rn}$ and ${ }^{220} \mathrm{Rn}$ inhalation exposure were obviously

(ELCR) in three age groups; comparison with Turkey average (before pandemic) and average worldwide 
Fig. 1 The outdoor occupancy factor variation during the time for three groups for ELCR estimation

Fig. 2 The indoor occupancy factor variation during the time for three groups for ELCR estimation
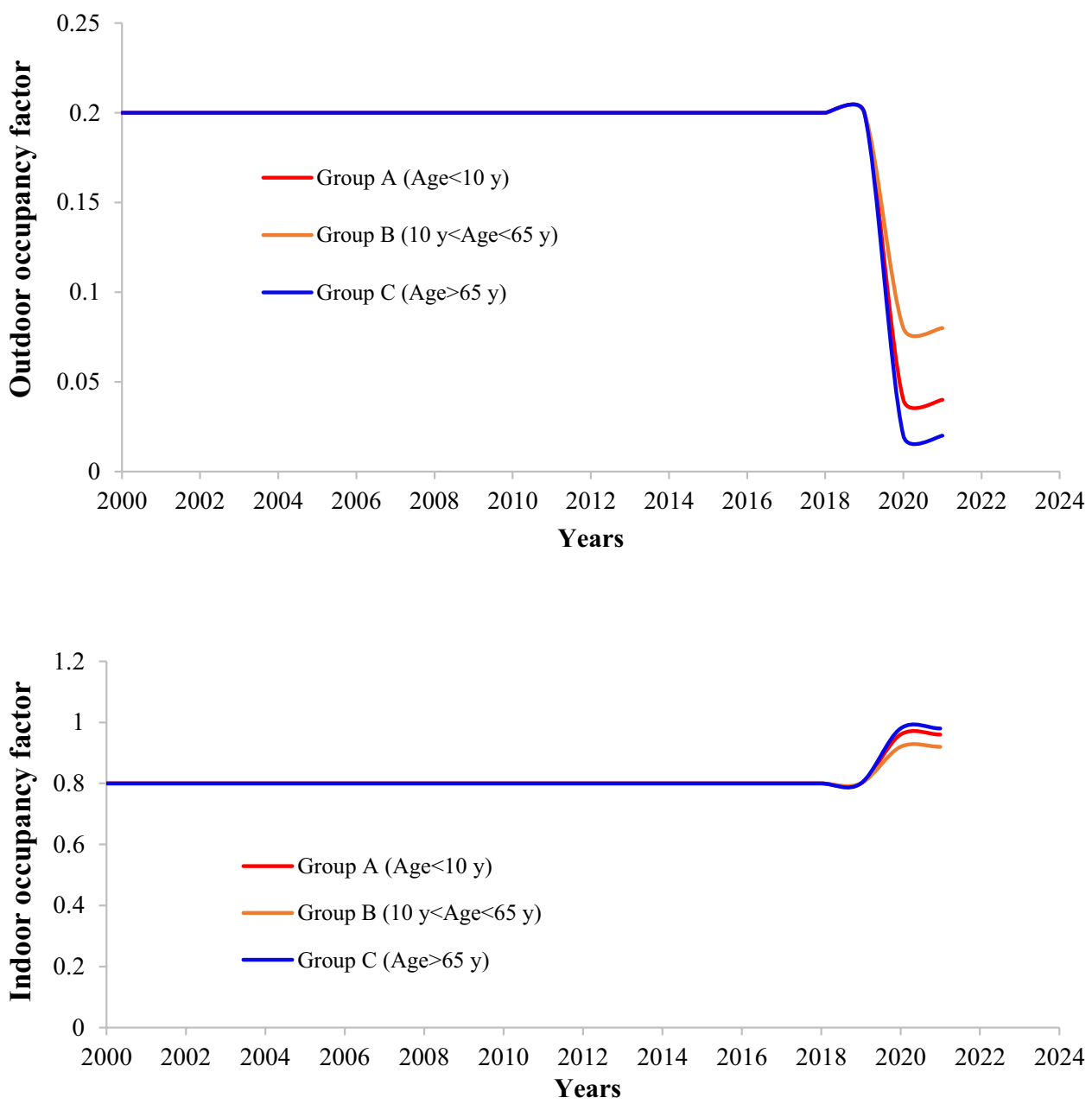

Fig. 3 The outdoor occupancy factor changes during COVID19 pandemic lockdown for three age groups

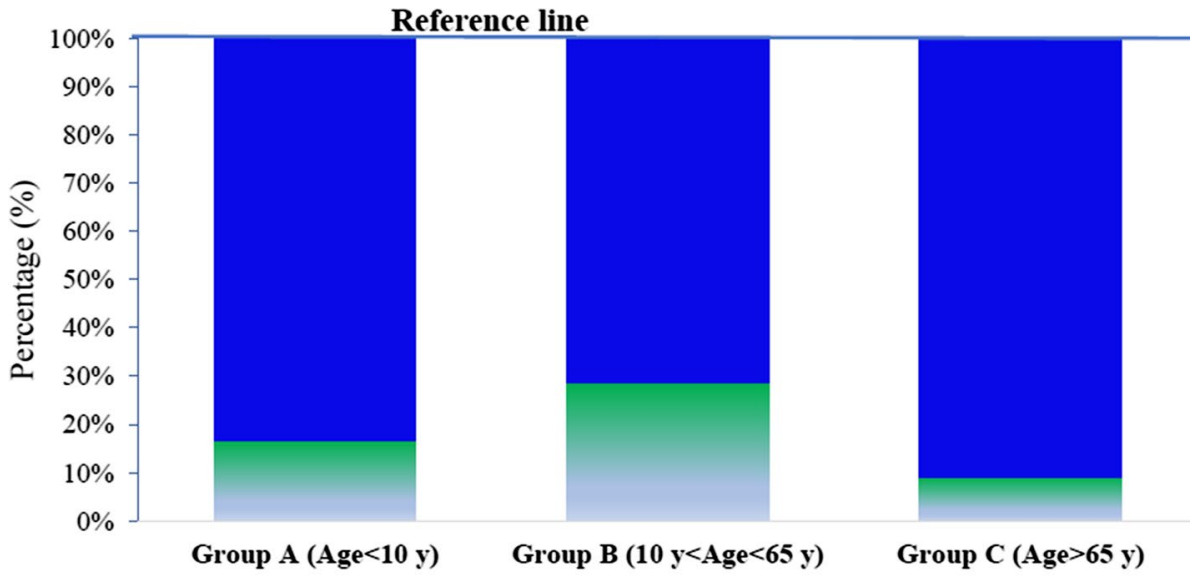

- Reference outdoor occupancy factor Outdoor occupancy factor observed. At the same time, the variation in ${ }^{220} \mathrm{Rn}$ was higher than ${ }^{222} \mathrm{Rn}$. This difference can be because of dose conversion factors (DCF). According to the ICRP report's current DCF for thoron and radon, [19].
Also, the excess lifetime cancer risk was affected by lockdown. By considering pandemic duration from this research (approximately 13 months), the results calculated Eqs. 2 and 4, shown in Fig. 6. According to this research, the 
Fig. 4 The indoor occupancy factor changes during COVID-

19 pandemic lockdown for three age groups

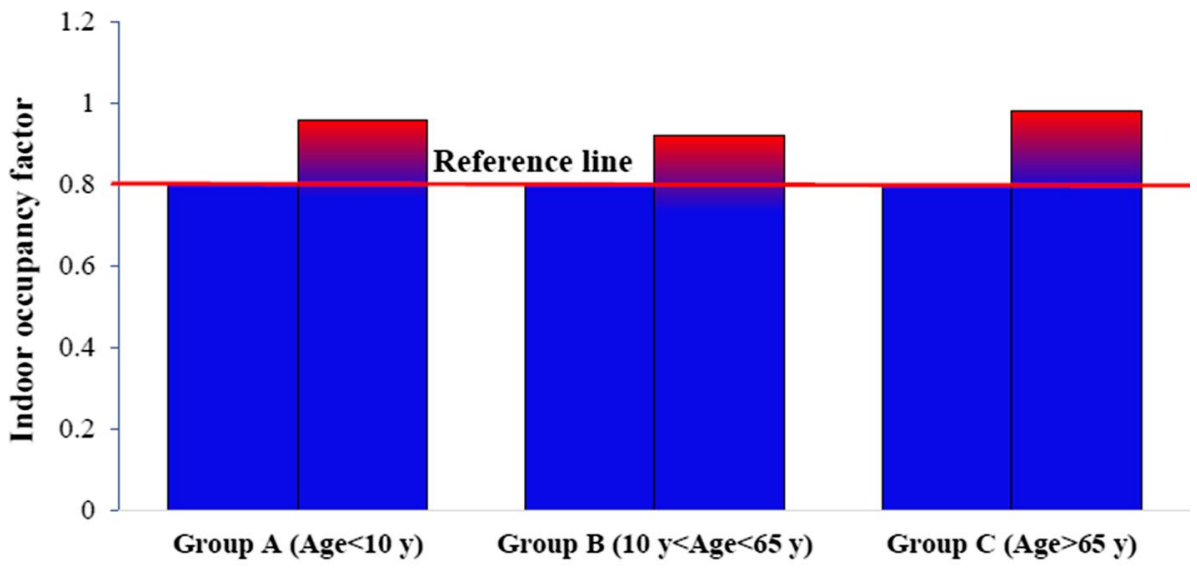

$\square$ Reference indoor occupancy factor
Indoor occupancy factor excess lifetime cancer risk value of three groups were compared the world average value and shown increased value between 1 and 3\% in the pandemic period. In comparison, this difference value for group A, group B, and group C was obtained at $1.7 \%, 1.3 \%$, and $2.1 \%$, respectively (Fig. 6). Also, the comparing of ELCR results with Turkey average value before pandemic period exposure to ${ }^{222} \mathrm{Rn}$ (regardless of ${ }^{220} \mathrm{Rn}$ portion because of data lack) shown $20.4 \%$, $20 \%$, and $21 \%$ increasing in group A, group B, and group $\mathrm{C}$, respectively.

According to the UNSCEAR 2000, the global average exposure to natural radioactive sources is estimated to be $2.4 \mathrm{mSv} \mathrm{y}^{-1}$, of which 0.48 is related to extra gamma radiation annual effective dose from total external terrestrial radiation available radioactive materials in the earth's crust and 1.25 is due to ${ }^{222} \mathrm{Rn}$ and ${ }^{220} \mathrm{Rn}$ gases. This research indicated $3.68 \mathrm{mSv} \mathrm{y}^{-1}, 3.60 \mathrm{mSv} \mathrm{y}^{-1}$, and $3.71 \mathrm{mSv} \mathrm{y}^{-1}$ for group A, group $\mathrm{B}$, and group $\mathrm{C}$, respectively. The comparing of those results with global average exposure to natural radioactive sources shown 53\%, 50\%, and 54\% increasing in group A, group $\mathrm{B}$, and group $\mathrm{C}$, respectively.

\section{Conclusions}

In this study, the COVID-19 pneumonic lockdown effects have been investigated in outdoor and indoor gamma radiation annual effective dose, ${ }^{222} \mathrm{Rn}$ and ${ }^{220} \mathrm{Rn}$ inhalation exposure, and excess lifetime cancer risk (ELCR) in three age groups. The occupancy factor variation is caused by the risk parameters changes. Hence, the worldwide average outdoor and indoor gamma radiation annual effective dose, ${ }^{222} \mathrm{Rn}$ and ${ }^{220} \mathrm{Rn}$ inhalation exposure, and excess lifetime cancer risk (ELCR) were calculated with corrected occupancy factor, supposing all parameters as the constant value reported in UNSCEAR 2000. The new occupancy factor showed the most decreasing effect in calculating the outdoor gamma radiation annual effective dose of age group $\mathrm{C}$. This factor also has the most increasing effect in calculating the indoor gamma radiation annual effective dose of age group $\mathrm{C}$. The ${ }^{222} \mathrm{Rn}$ inhalation exposure value difference was observed higher than ${ }^{220} \mathrm{Rn}$ inhalation exposure value difference gamma radiation annual effective dose. This study shows the excess lifetime cancer risk value of three groups was increased for group A (1.7\%), group B (1.3\%), and group C (2.1\%) due to 13 months pandemic period. Finally, this study results will be beneficial for future researchers to predict the annual gamma dose rate and excess lifetime cancer risk during and after the pandemic situation. 
Fig. 5 a Changes in ${ }^{222} \mathrm{Rn} \mathbf{b}$ in

${ }^{220} \mathrm{Rn}$ inhalation exposure of three age groups due to pandemic situation

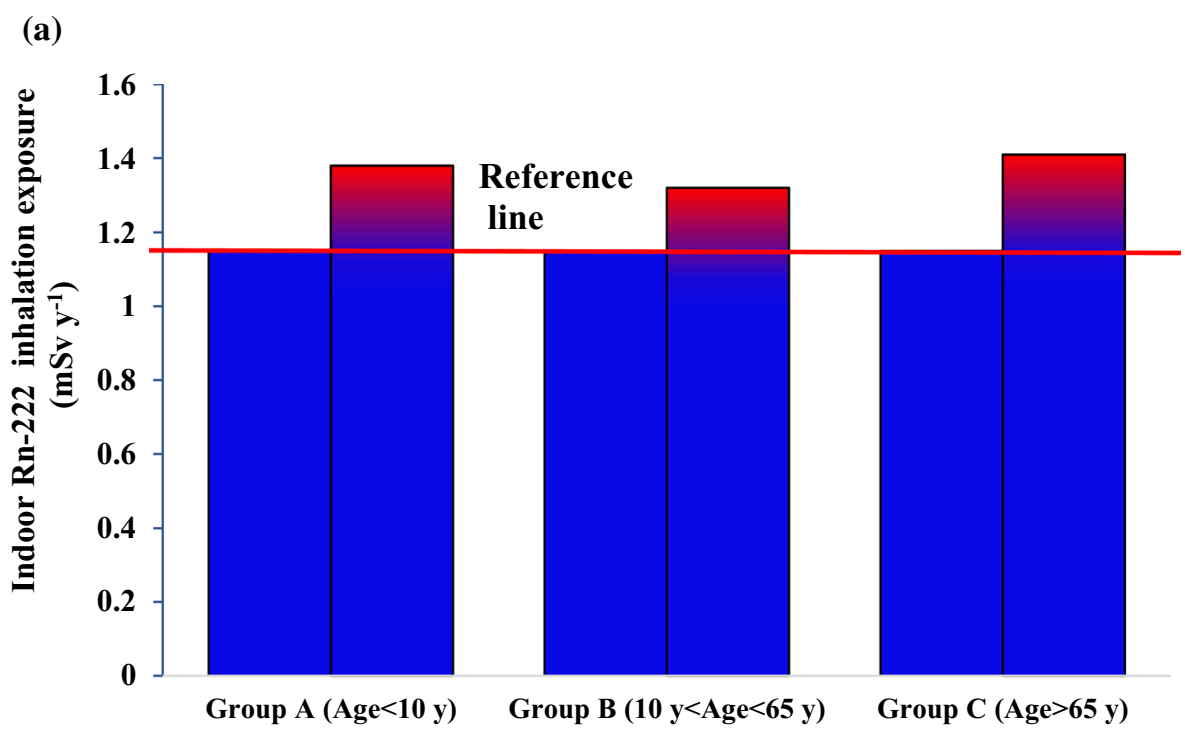

$\square$ Worldwide reference

a Lockdown value

(b)

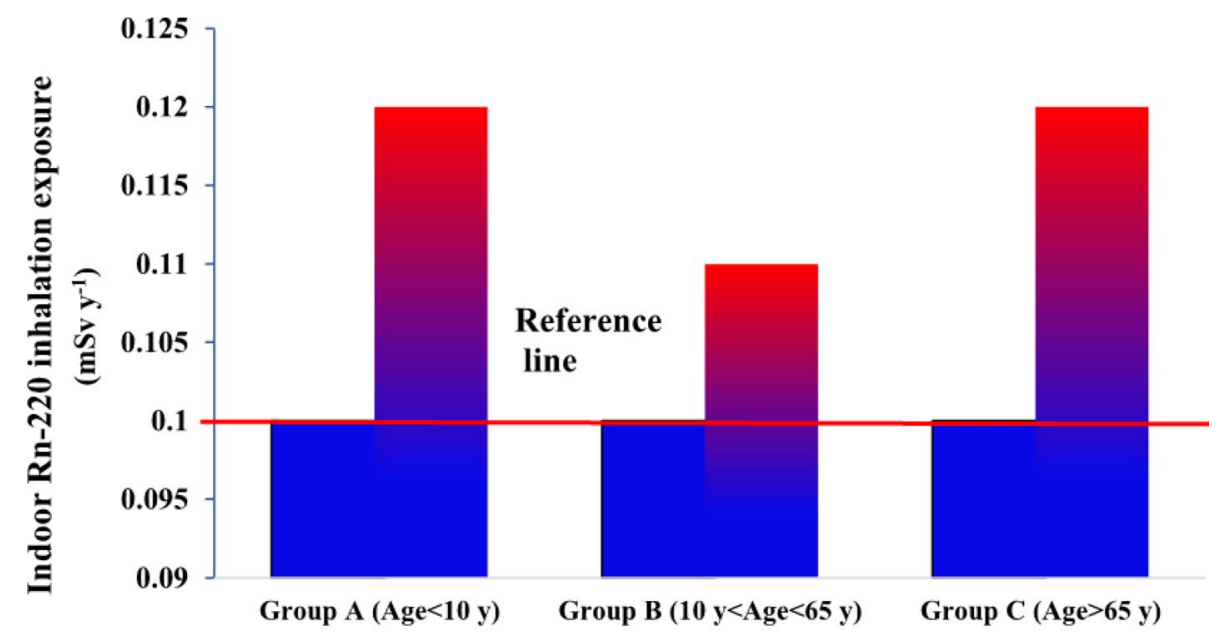

$\square$ Worldwide reference

Eockdown value 
Fig. 6 The excess lifetime cancer risk (ELCR) value of three age groups after and before of lockdown

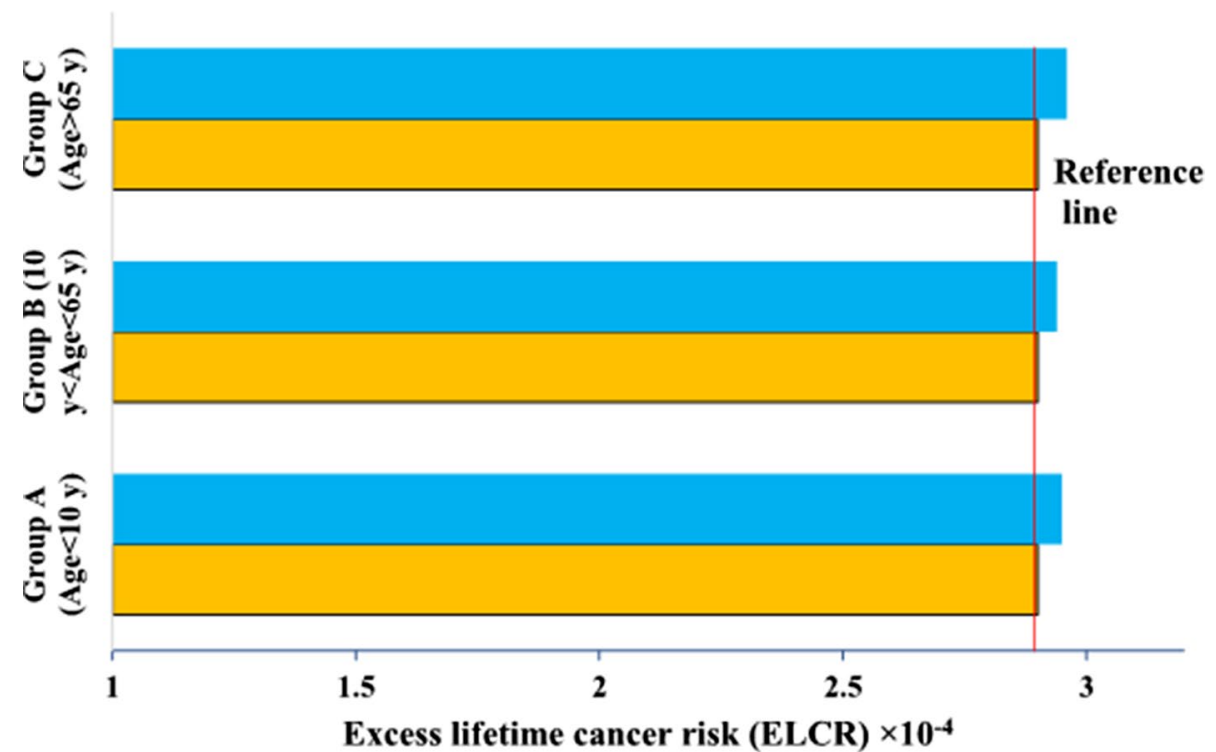

- Lockdown effect $\square$ Worldwide reference
Acknowledgements This research was supported by Project No (TURSP-2020/45) Taif University, Saudi Arabia. Also, the authors are grateful to the University of Kyrenia research group for the use of their facilities.

\section{Declarations}

Conflict of interest The authors state that they have no known conflicting financial or personal interest that might have impacted the work presented in this study.

\section{References}

1. Wang C, Horby PW, Hayden FG, Gao GF (2020) A novel coronavirus outbreak of global health concern. Lancet 395:470-473

2. Johns Hopkins University \& Medicine (2021) Johns Hopkins Univ Coronavirus Resour Cent. Available at: https://coronavirus.jhu. edu

3. UNSCEAR (2000) Sources and effects of ionizing radiation. In Report of the United Nations scientific committee on the effects of atomic radiation to the general assembly. New York: United Nations

4. Abbasi A, Mirekhtiary SF (2020) Radiological impacts in the high-level natural radiation exposure area residents in the Ramsar. Iran Eur Phys J Plus. https://doi.org/10.1140/epjp/ s13360-020-00306-x

5. Abbasi A, Mirekhtiary F (2018) Risk assessment due to various terrestrial radionuclides concentrations scenarios. Int J Radiat Biol 95(2):179-185

6. Maya J, Mohamadou L, Mbembe SM et al (2020) Radon risks assessment with the COVID-19 lockdown effects. J Appl Math Phys 8:1402

7. Abbasi A (2013) Calculation of gamma radiation dose rate and radon concentration due to granites used as building materials in Iran. Radiat Prot Dosim 155:335-342. https://doi.org/10. 1093/rpd/nct003

8. Abbasi A (2017) Modeling of lung cancer risk due to radon exhalation of granite stone in dwelling houses. J Cancer Res Ther 13:208. https://doi.org/10.4103/0973-1482.204851

9. Abbasi A, Mirekhtiary F (2011) Survey gamma radiation measurementsin commercially-used natural Tiling rocks in Iran. World Acad Sci Eng Technol Int J Math Comput Phys Electr Comput Eng 5:561-567

10. Abbasi, A., \& Hassanzadeh, M. (2017) Measurement and Monte Carlo simulation of $\gamma$-ray dose rate in high-exposure building materials. Nuclear Sci Tech 28(2):1-5

11. Sannappa J, Suresh S, Rangaswamy DR, Srinivasa E (2020) Estimation of ambient gamma radiation dose and drinking water radon concentration in coastal taluks of Uttara Kannada district, Karnataka. J Radioanal Nucl Chem 323:1459-1466

12. UNSCEAR (1993) Sources and Effects of Ionizing Radiation. United Nations Scientific Committee on the Effects of Atomic Radiation, United Nations, New York

13. Protection R (2007) ICRP publication 103. Ann ICRP $37: 2$

14. Celebi N, Ataksor B, Taskın H, Bingoldag NA (2015) Indoor radon measurements in Turkey dwellings. Radiat Prot Dosimetry 167:626-632

15. United Nations Scientific Committee on the Effects of Atomic Radiation (2017) Sources, Effects and Risks of Ionizing Radiation, United Nations Scientific Committee on the Effects of Atomic Radiation (UNSCEAR) 2016 Report: Report to the General Assembly, with Scientific Annexes. United Nations

16. Silva ECR, Silva-Filho EV (2020) Radon concentration and radiation exposure levels in workplace buildings of downtown Rio de Janeiro City, SE, Brazil. J Radioanal Nucl Chem 326:1709-1717

17. Türkiye Cumhuriyeti İçişleri Bakanlığı (2021) Şehir Giriş/Çıkış Tebirleri ve Yaş Sınırlaması. Available at; https://www.icisleri. gov.tr/sehir-giriscikis-tebirleri-ve-yas-sinirlamasi. Accessed 30 March 2020

18. United Nations Scientific Committee on the Effects of Atomic Radiation (2008) Annex B: Exposures of the public and workers 
from various sources of radiation. UNSCEAR 2008 Rep Sources Ioniz Radiat

19. Paquet F, Bailey MR, Leggett RW et al (2017) ICRP publication 137: occupational intakes of radionuclides: part 3. Ann ICRP 46:1-486
Publisher's Note Springer Nature remains neutral with regard to jurisdictional claims in published maps and institutional affiliations.

\section{Authors and Affiliations}

\section{Akbar Abbasi $^{1}$ (1) - Fatemeh Mirekhtiary ${ }^{2} \cdot$ A. El-Denglawey ${ }^{3} \cdot$ Hesham M. H. Zakaly $^{4,5}$}

$\bowtie$ Akbar Abbasi

akbar.abbasi@kyrenia.edu.tr

A. El-Denglawey

a.denglawey@tu.edu.sa

Hesham M. H. Zakaly

h.m.zakaly@azhar.edu.eg

1 Faculty of Engineering, University of Kyrenia, Kyrenia, North Cyprus, Mersin 10, Turkey

2 Faculty of Engineering, Near East University, Nicosia, North Cyprus, Mersin 10, Turkey
3 Department of Physics, College of University College at Turabah, Taif University, P.O. Box 11099, Taif 21944, Saudi Arabia

4 Department of Physics, Faculty of Science, Al-Azhar University, Assiut 71542, Egypt

5 Institute of Physics and Technology, Ural Federal University, Yekaterinburg, Russia 620002 